\title{
EFFECT OF SANDBLASTING ON CADMIUM FREE COMPLETE DENTURE RETENTION
}

\author{
Nancy Nader El-Sherbini* and Mai Adel Helmy*
}

\begin{abstract}
This study was performed to compare the impact of the sandblasting on the retention of the complete dentures made from two different denture base materials.

Materials and methods: Twenty patients were selected to construct complete dentures with the fitting surface treated by sandblasting using alumina particles $50 \mu$ in diameter. They were randomly divided into two groups: Group A patients received complete dentures constructed from (poly methyl methacrylate) PMMA long cycle heat cure acrylic resin \& Group B: Patients received complete dentures constructed from cadmium-free heat cured acrylic resin. The retention was measured for the two denture base materials (cadmium free and cadmium containing materials before and after sandblasting the fitting surface using Digital force gauge.
\end{abstract}

Results: There was statistically significant increase in the retention values of the cadmium free material than that of the conventional material before and after sandblasting.

KEYWORDS: Denture base materials, Retention, Sandblasting

\section{INTRODUCTION}

People increasingly wish their natural tooth to continue functioning rather than using dentures, a degree of prejudice against dentures appears to exist. The introduction of more advanced treatment modalities despite for completely edentulous cases yet the need for complete denture as a treatment option will probably continue., ${ }^{1,2}$

Different denture base materials are present in the market. Both metallic as (gold alloys, Co-Cr, silver palladium, nickel chromium and titanium bases) or non-metallic bases as PMMA, flexible denture base materials and fiber reinforced denture base materials. PMMA materials remain the most popular due to its low cost, relative ease of use, and reliance on simple processing equipment. ${ }^{3,4}$

The Cadmium pigments are inorganic stable coloring agents which can be produced in a range of brilliant shades of yellow, orange, red and maroon. ${ }^{5}$ Their greatest use is in plastics but they also have significant application in ceramics, glasses and specialist paints. Cadmium poisoning due to the

* Lecturers at the Removable Prosthodontics Department, Faculty of Dentistry, Cairo university 
excessive exposure to cadmium vapor, if inside the human body, cadmium is harmful. There are high levels of toxic compounds inside cadmium that can pose a serious threat to living organisms and our ecosystem. .,6 $^{5}$

Burning mouth syndrome due to cadmium in a denture wearer was founded more in a female denture wearer. Patch tests were performed and gave positive results only to a $2 \%$ petrolatum cadmium sulfate, which was present in the denture. Removal of the denture lead to the clearing up of oral symptoms in 3 days. $^{6}$ This lead to the introduction of the cadmium-free PMMA denture base materials in the recent past several years to study the effect of this element absence on the qualities of complete denture. Cadmium-free denture base materials are available as long cycle heat cure, quick cure, cold cure, flexible materials and repair materials. ${ }^{5}$

Denture retention is one of the most important qualities to be considered for denture success. The close adaptation of the base to the supporting tissues and the smaller space between the fitting surface and supporting structure the more adaptation, the more retention is achieved., ${ }^{7,8}$ Also most patients are primarily satisfied with their dentures when they are retentive. Several factors in the oral cavity influenced the retention of complete dentures as mechanical, physical, physiological and biological factors. ${ }^{9}$

Saliva plays an important role for denture retention through its viscosity, adhesive quality of the salivary film and its thickness, cohesive forces between the base and saliva, the surface energy of the denture base and surface tension of saliva and so its ability to spread on the fitting surface..$^{10-12}$

Methods to study ways to improve retention were carried out by many researchers; one of these methods is sandblasting using particles of various sizes and use of a thin layer of adhesive materials..$^{13,14}$

Different techniques such as strain gauges force transducers and hydrolytic systems using extra oral transducers have been utilized to measure the denture retention. ${ }^{15-18}$

\section{MATERIALS AND METHODS}

Twenty male patients were selected from those attending the Outpatient Clinic, Removable Prosthodontics Department, Faculty of Dentistry, Cairo University. In this study patients were evaluated for the following criteria:

Inclusion criteria for the patients:

- Good oral hygiene

- Good Mental attitude regarding (House classification).

- $\quad$ Free from any systemic diseases or controlled systemic diseases, specially patients with diseases that might affect the bone quality and quantity.

- All cases with Angle's class I jaw relationship.

Exclusion criteria for the patients:

- Heavy Smokers to avoid mucosal inflammation.

- Bad habits as bruxism or clenching to avoid forces on the residual ridge

- Oral diseases or mucosal undercuts and allergy to any dental material.

- Neuromuscular disorders were excluded from the study, e.g. Parkinsonism

- Uncooperative patients.

The participants were informed about the study, and a written informed consent was obtained from them.

Steps of dentures construction: Primary impressions for the edentulous ridges were made using alginate impression material, and the diagnostic casts were poured in dental stone (Type III, GypstonePrevestDentpro). The custom tray was fabricated on study cast in auto-polymerizing acrylic 
resin (DPI Bombay Burmah Trading Corporation Ltd.), After that, border molding was done by manual and functional movements using low fusing compound green (Tropicalgin, Zhermack, Italy), then secondary impression was made with Zinc oxide Eugenol impression paste (DPI). After verification, the impression was poured in Dental Stone (Type III), and the master cast was fabricated.

Maxillary face bow record was made to mount the upper cast on a Semi adjustable articulator HANAU H (Arcon, Louisville, KY USA 40209); the mandibular cast was mounted according to a centric relation record obtained from the patient using the check bite technique. Finally a protrusive record was essential to adjust the horizontal condylar guidance of the articulator. Then, Teeth were set up according to the lingualized concept to obtain a more stable denture.

\section{Patient grouping:}

After the try in stage has been carried out for all patients, the patients were randomly divided using closed envelopes into two groups ten patients in each. Group A: Ten patients received complete dentures cured (poly methyl methacrylate) PMMA long cycle heat cure acrylic resin (Pala, Kulzer, Germany) Group B: Ten patients received complete dentures cured of cadmium-free long cycle heat cured (Axcent,Garreco,USA) Axcent acrylic resin.

Waxing up, investing and boiling out was carried out as usual. Then, Mixing and packing were carried out as the following:

\section{A) Complete dentures cured of PMMA long cycle acrylic resin:}

One part of liquid was added to three parts of powder; spatulated approximately for 45 seconds. When the mix reaches the dough stage mix was transferred to the flask and packed. The flask was then closed to full metal closure until over flow was noticed then put in water bath and temperature was gradually raised to $65 \mathrm{C}^{0}$ within 30 minutes. The temperature was raised to $80 \mathrm{C}^{0}$ within 8 hours. Finally the temperature was raised to the boiling point and left for 30 mintues. Finally the flask was allowed to bench cool for 45 minutes before deflasking.

\section{B) Complete dentures cured of cadmium-free heat cured acrylic resin.}

One part of liquid was added to three parts of powder; spatulated approximately for 45 seconds. The mix was then left until it had reached the dough stage approximately after 3-5 seconds. The mix was then transferred to the warm gypsum mold $45 \mathrm{C}^{0}$ and pat into place with fingers covered with moist cellophane. The flask was then closed immediately to full metal closure until over flow was noted. The flask was then left for bench set for 30 minutes before curing to allow the acrylic to reach complete equilibrium. Curing was then done at $75 \mathrm{C}^{0}$ for 8 hours then left for 30 mintues in boiling water. Finally the flask was allowed to bench cool for 45 minutes before deflasking.

Finishing and polishing was made as usual for both groups.

\section{Measurement of retention of denture bases:}

The digital force gauge (Lutron FG 5000 A) was used for the test. The measuring unit for retention was adjusted to be in Kilogram. In the geometrical centre of all dentures a screw was fixed for further connection of the force gauge. The geometrical center was determined by the intersection of the lines joining the canine eminence and the hamular notch.

Retention was measured for both groups on the day of denture insertion after leaving the denture for 5 minutes in the patient's mouth with the patient biting on a cotton roll one on each side. During the measuring procedure, the patients were seated in an upright position and were asked to open their mouth so that their maxillary occlusal plane was oriented 
parallel to the horizontal plane. The Digital force gauge was attached to the hook. This position was important so that the dislodging force will be almost perpendicular to the maxillary occlusal plane for accuracy of the results obtained. (Fig. 1)

Sandblasting the denture bases: After retention was measured for all patients, the dentures of both groups were sandblasted as follows: (Fig. 2)

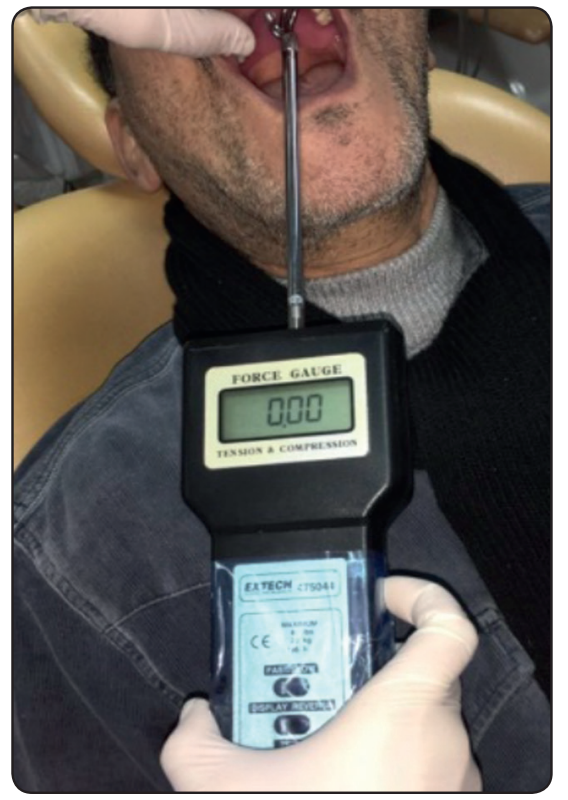

Fig. (1) The digital force gauge

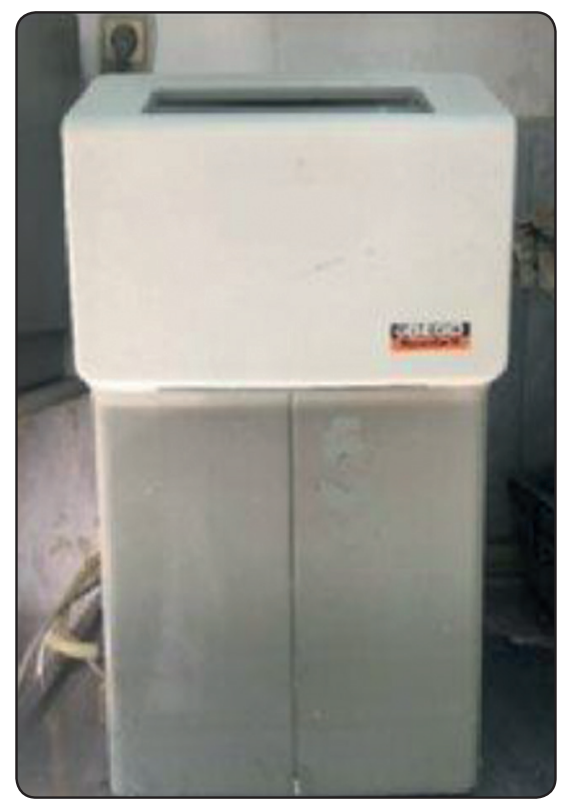

Fig. (2) Sandblasting machine
Sandblasting was performed using sandblasting machine (Wilhelm-Herbst-Straße 1 28359 Bremen, Germany). First, the internal surface of acrylic base borders was covered with aluminum foil $(1 \mathrm{~mm})$ to protect the borders. Then, using alumina particles $50 \mu$ in diameter, sandblasting was performed under 2-2.5 bar pressure for one minute with $10 \mathrm{~cm}$ distance from the nozzle. However, sandblasting by alumina particles with a spherical shape, which created circular or semi-circular crosssection depressions without undercuts. Thus, they can be easily cleaned.

After the dentures were sandblasted again retention was measured with the force gauge with the same procedure previously discussed.

\section{RESULTS}

This study was conducted to compare the retention of two denture base materials (cadmium free and cadmium containing long curing cycle Polymethyl methacrylate acrylic resin before and after sandblasting the fitting surface. Data were analysed using SPSS 17 (SPSS Inc, Chicago, IL, USA). One-way ANOVA test was used to compare the retention values and the post-hoc Tuckey's test. (Table 1)

The mean retentive value for the cadmium free material before sandblasting was $\left(7.9+\_0.51\right) \mathrm{kg}$ while that for the conventional material the mean retentive value was $(4.3 \pm 1.01) \mathrm{kg}$.

The mean retentive value for the cadmium free material after sandblasting was $(13.1 \pm 1.04) \mathrm{kg}$ while that for the conventional material the mean retentive value was $(8.7 \pm 0.75) \mathrm{kg}$

Regarding comparing retention before sandblasting the cadmium free material showed statistically significant higher retention values compared to the conventional material. $\mathrm{P}>0.001$

When comparing the retention values of the cadmium free material after sandblasting to those of the conventional material after sandblasting 
there was statistically significant difference in the retention. $>0.001$

TABLE (1) Showing the values of retention for the two materials represented as mean and standard deviation.

\begin{tabular}{|c|c|c|}
\hline Material & Mean & SD \\
\hline $\begin{array}{c}\text { Cadmium free material before } \\
\text { sandblasting }\end{array}$ & 7.9 & 0.51 \\
\hline $\begin{array}{c}\text { Cadmium free material after } \\
\text { sandblasting }\end{array}$ & 13.1 & 0.75 \\
\hline $\begin{array}{c}\text { Conventional material before } \\
\text { sandblasting }\end{array}$ & 4.3 & 1.01 \\
\hline $\begin{array}{c}\text { Conventional material after } \\
\text { sandblasting }\end{array}$ & 8.7 & 0.75 \\
\hline
\end{tabular}

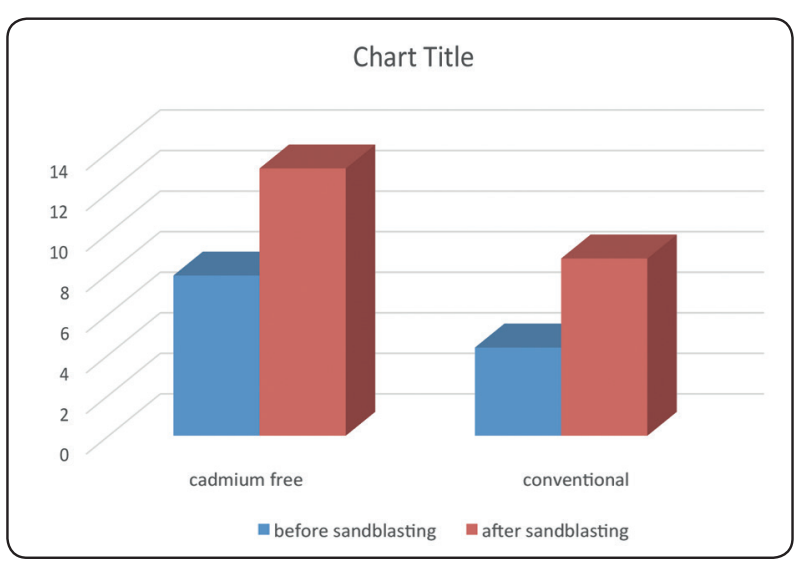

FIG. (3) Bar chart showing the difference in the retention values between cadmium free and conventional denture base materials.

\section{DISCUSSION}

Patient satisfaction with removable complete denture is the most important goal of the clinical work. Also denture retention is among the most important factors regarding this goal. Various attempts have been made to improve its wettability and retention by surface modification procedures like sandblasting the fitting surface of dentures. ${ }^{19,21}$

Polymethyl methacrylate (PMMA) is the most commonly used denture base material, yet it has low surface energy and so the ability of saliva film to spread over the fitting surface is a critical condition. It is claimed that cadmium used as a coloring agent in conventional polymethyl methacrylate base material is toxic and may cause irritation or toxicity. Cadmium-free denture base material was chosen to be compared with the conventional PMMA, since there is an approach to avoid using the cadmium containing material due to the known hazards of cadmium. Cadmium free material was selected to study the effect of cadmium removal from the composition of the conventional denture base materials on the retentive quality of complete denture.Cadmium-free denture base material showed higher retention values compared to the conventional material. This may be attributed to that the absence of cadmium might have affected the amount of dimensional changes occurring during material curing resulting in a more accurate denture base and hence better retention.

The significant increase in retention of denture bases after sandblasting for both types of denture bases as sandblasting produced a rough or a porous surface and encourages saliva droplets to be entrapped in these pores, which render the resin surface more hydrophilic and so increased the area covered by saliva and Consequently, more resistance will be offered by the meniscus to recede at the denture tissue interface hence improved retention. ${ }^{21-23}$

Moreover, Sandblasting increases wettability of the denture bases by decreasing the advancing contact angle. ${ }^{24}$ However, further studies are required in this respect.

\section{CONCLUSION}

Within the limits of this study it was conclude that the cadmium- free denture base materials had good and satisfying retentive results compared to the conventional denture base materials to guard against the hazardous effects of cadmium. 


\section{Conflict of interest:}

The author denies any conflict of interest.

\section{REFERENCES}

1. Bilhan H, Erdogan O, Ergin S, Celik M, Ates G, Geckili O. : Complication rates and patient satisfaction with removable dentures. J Adv Prosthodont.2012; 4: 109-115

2. Kumar MV, Bhagath S, Brintha JJ. : Historical interest in denture base materials. SRM University J Dent Sci. 2010;1:103-105.

3. Fernandez MA, Nimmo A, Behar-Horenstein LS.:.Digital Denture Fabrication in Pre- and Postdoctoral Education: A Survey of U.S. Dental Schools. J Prosthodont. 2016; 25:83-90

4. Singh JP, Dhiman RK, Bedi RP, Girish SH. :Flexible denture base material: A viable alternative to conventional acrylic denture base material. Contemp Clin Dent. 2011;2:313-317.

5. Bernard A. :Cadmium \& its adverse effects on human health. Indian J Med Res. 2008;128: 557-564.

6. Purello-D'Ambrosio F, Gangemi S, Minciullo P, Ricciardi L, Merendino RA: Burning mouth syndrome due to cadmium in a denture wearer. J Investig Allergol Clin Immunol. 2000;10:105-106.

7. Zarb G, Hobkirk J, Eckert S, Jacob R. :Prosthodontic treatment for edentulous patients. $13^{\text {th }}$ Ed. USA: Elsevier; 2012,53-90.

8. Murray M D, Darvell B W. :The evolution of the complete denture base. Theories of complete denture retention - A review. Austral Dent J. 1993; 38: 216-455.

9. Darvell BW, Clark RK.: The physical mechanisms of complete denture retention. Brit Dent J. 2000;189:248-252.

10. Husham AM, Al-Bazirgan MH.: Effect of air abrasion on the retention and texture of the maxillary complete denture. Am J Dent. 2006;19:115-122.

11. Sipahi C, Beyzadeoglu M, Demirtas S, Ozen J. :Effect of different mucosal and acrylic resin surface treatments in a denture retention model for patients with radiotherapyinduced Xerostomia. Int J Prosthodont. 2007; 20:405-408.

12. Wang Z, Shen MM, Liu XJ, Si Y, Yu GY. :Characteristics of the saliva flow rates of minor salivary glands in healthy people. Arch Oral Biol. 2015;60:385-390

13. Sharma S, Gupta V, Godbole SR.:Effect of the surface texture of intaglio surface on Denture Retention- An In vivo Analysis. Chatting are J Health Sci. 2013;1:35-39.

14. Hemmati MA, Jamali A, Barzegar S , Taghavi F. Effect of Sandblasting on Retention of Maxillary Complete Denture.2015;27:116-120

15. Gupta RA, Luthra R P , Kumar N.: Comparative analysis of retention of denture bases without and after surface treatment of basal surface with different sizes of alumina particles -An in vivo study.J Adv Med and Dent. Sci. Res. 2015;3:102-108

16. Sipahi C, Beyzadeoglu M, Demirtas S, Ozen J.: Effect of different mucosal and acrylic resin surface treatments in a denture retention model for patients with radiotherapyinduced Xerostomia. Int J Prosthodont. 2007; 20:405-408.

17. Hemmati MA, Jamali A, Barzegar S, Taghavi F. :Effect of Sandblasting on Retention of Maxillary Complete Denture J Islamic Dent Assoc IRAN. 2015; 27:116-120.

18. Kikuchi M, Ghani F, Watanabe M. :Method for enhancing retention in complete denture bases. J Prosthet Dent. 1999; 81:399-403.

19. Cavalcanti YW, Bertolini MM, Cury AA, da Silva WJ.: The effect of poly(methyl methacrylate) surface treatments on the adhesion of silicone-based resilient denture liners. J Prosthet Dent. 2014;112:1539-1544.

20. Gupta1 R, RLuthra RP, Kumar N: A comparative analysis of retention of denture bases without and after surface treatment of basal surface with different sizes of alumina particles - an in vivo study J Adv Med Dent Scie 2015; 3:102-108

21. Chandu GS Hema Ha Mahajan BS Azad A et al. :A comparative study of retention of complete denture base with different types of posterior palatal seals - an in vivo study Clin Cosmet Investig Dent. 2014; 6: 95-100.

22. Neale M. Harvey, Gleb E. Yakubov, Jason R. Stokes \& Jacob Klein: Lubrication and load-bearing properties of human salivary pellicles adsorbed ex vivo on molecularly smooth substrata. Biofouling. 2012;28 843-856

23. Karakis D, Akay C, Oncul B, Rad AY, Dogan A.Effectiveness of disinfectants on the adherence of Candida albicans to denture base resins with different surface textures. J Oral Sci. 2016;58;431-7

24. Al-Kheraif A A: The effect of mechanical and chemical polishing techniques on the surface roughness of heatpolymerized and visible light-polymerized acrylic denture base resins. Saud Dent J.:2014; 26:56-62 